\title{
Carta inédita de Jerónimo Pietas al rey Felipe V de España, 1723
}

\author{
Francis Goicovich ${ }^{1}$
}

A Icha, por su compañía.

Los informes de Jerónimo Pietas y Garcés, funcionario imperial que arribó a las australes latitudes del Reino de Chile hacia 1681, según se desprende del escrito que socializamos al círculo de especialistas por este medio², han sido bañados por la tinta de la imprenta solo en dos ocasiones: el primero fue publicado a mediados del siglo XIX fruto del esfuerzo del erudito francés Claudio Gay, quien lo incorporó en el primer tomo documental de su Historia Física y Política de Chile (1846: 486-512); el segundo, de redacción más temprana, lo fue hace poco más de una década como resultado de nuestras indagaciones en el Fondo Carlos Morla Vicuña de la Biblioteca Nacional de Santiago (Goicovich, 2005). Ambos textos, absolutamente complementarios en su información aunque no exentos de datos contradictorios, tal y como demostró la aproximación comparativa que hicimos tiempo atrás (Goicovich, 2005: 208-213), configuran una radiografía bastante acabada del emplazamiento de cada grupo étnico, el temple de sus habitantes, sus armas y modo de combatir, proponiendo las medidas más adecuadas para alcanzar su pacificación.

La epístola que centra nuestra atención fue escrita en medio de la difícil coyuntura que atravesaba por entonces la frontera del Biobío. Desde el reinado de Felipe II se tenía clara conciencia de que la Guerra de Arauco era un conflicto desgastante y oneroso, que día a día demandaba una importante sangría en hombres y recursos para la monarquía: solo entre 1601 y 1658 se habían desembolsado 16.109.663 y tres reales y medio (Encina, 1983a: 119), lo que la convertía en la frontera más costosa de mantener en el continente. Peor aún, la irregularidad en el envío del Real Situado desde el Virreinato

1 Chileno. Académico, Departamento de Ciencias Históricas, Universidad de Chile. Ph.D. (c) in History, Latin American Studies, University of Texas at Austin. Email: fgoicovi@uchile.cl. El trabajo de archivo se realizó con el apoyo de la beca de investigación "College of Liberal Arts Graduate Research Fellowship" de la Universidad de Texas en Austin, y de la "FulbrightLaspau Summer Field Research Grant" de los Estados Unidos. Extiendo mi sincera gratitud al personal del Salón José Toribio Medina de la Biblioteca Nacional de Santiago de Chile por su acogida y excelente disposición.

2 "Carta de don Jerónimo Pietas y Garcés al rey sobre la Guerra de Arauco y el estado general del Reino de Chile; Chillán, 3 de octubre de 1723", BNOM, tomo 309, fs. 39-47v. La compaginación del texto está desordenada, iniciándose su lectura en la foja 40. 
del Perú, y el inescrupuloso manejo que hacían de su distribución virreyes, gobernantes y oficiales reales, eran ingredientes que sazonaban un lucrativo caldo de corrupción. Así, por ejemplo, ese mismo año se envió un informe al monarca acusando que "en los seis años corridos desde 1718 [h]asta el presente de 1723, solo [h]an venido 379 mil pesos, reduzida la maior parte a géneros de ropa de mala calidad y a suvidos precios, en que se debe considerar el gran descaezimiento a que puede haver llegado el exerzito y sus plazas con la falta de tantos años de paga" ${ }^{3}$. Es cierto que a partir de 1683 se constata un declive en la confrontación fronteriza (Goicovich, 2007: 325,331 ), en buena medida gracias a la actividad de los jesuitas que habían buscado por todos los medios llamar la atención del rey en lo referente a la necesidad de llevar adelante la conquista por medios no violentos, pero ello no obsta que los malones o incursiones depredadoras de los indígenas jamás desaparecieron, y que la amenaza de las rebeliones generales nunca fue erradicada del todo.

La carta de Jerónimo Pietas va más allá de ser una simple descripción de la situación en la región meridional del Reino, pues es un verdadero llamado de atención, un grito de alerta cargado de juicios negativos ante una realidad que el autor considera el resultado de una serie de malas decisiones tomadas por quienes detentaban las riendas de la gobernación. El contenido se divide en dos grandes temáticas: primero, una evaluación del estado en que se hallaba la posición española al sur del Biobío, explicando las causas de la penosa situación y denunciando la escasa visión de quienes tuvieron la oportunidad de revertir las cosas; segundo, una temprana referencia de la rebelión mapuche de 1723, cuando ésta recién comenzaba a generalizarse en la región fronteriza.

\section{Balance de la situación española en la frontera meridional del Reino de Chile}

Los méritos de Jerónimo Pietas en la gestión del espacio fronterizo, tanto en lo administrativo como en lo militar, le hicieron merecedor del rango de maestre de campo (Medina, 1906: 687). Como buen conocedor de la geografía física y social de la frontera, no es de extrañar que las autoridades solicitasen constantemente su consejo sobre diversos puntos concernientes a la Guerra de Arauco y el mejor modo de llevarla a feliz término. Ya en la

3 "Instrucción que se da al Comisario General don Diego de Encalada, Procurador nombrado por el ejército de este Reino de Chile para que pase a España a representar al Rey el nuevo alzamiento de los indios de él, y las calamidades que padece dicho ejército en la falta de paga y gente para las guarniciones de las plazas, defensa y conservación del Reino; Concepción, noviembre 12 de 1723", BNMM, tomo 180-181, f. 179. 
primera década del siglo XVIII, el gobernador Francisco Ibáñez de Peralta le encomendó la tarea de proporcionar al rey un acabado cuadro de los ritos y costumbres de los naturales, dando especial atención al estado de las edificaciones y tropas que sostenían la posición española en esos apartados rincones de Imperio. En un segundo informe solicitado por el mismo gobernador, dio cuenta del modo extraño en que los indios "hacían la guerra y cómo se sentaba y mantenía la paz", explicando las particularidades de su modo de combatir, "qual no se ve en otra nación alguna pues para ser exercito copioso era un enemigo duende que nunca se le hallaba cuerpo ni se afrontaba"4 . De seguro el informe de 1719 está inspirado, hasta cierto punto, en este tempranero texto ${ }^{5}$.

Pietas escribe con el convencimiento de que los informes redactados por solicitud de Ibáñez de Peralta nunca llegaron a manos del rey. La correspondencia, suponemos, pudo perderse en el trayecto, haber despertado escaso interés en los funcionarios del Consejo de Indias que seleccionaban los reportes de ultramar, o haber sido arrumbada por simple descuido en los archivos reales, lo que es plausible considerando el incontable número de papeles que a diario ponían a prueba la capacidad de gestión de la burocracia peninsular. De no haber acontecido este extravío, afirma el oficial, el soberano hubiese dispuesto de una completa evaluación del deplorable estado en que se encontraba el Reino, con lo que hubiese sido capaz de tomar las medidas más adecuadas para la pronta reparación de sus necesidades y previsión de calamidades futuras. Ante esta carencia, los males inevitablemente se habían perpetuado.

En su misiva de 1723, Jerónimo Pietas dibuja un panorama desalentador de la situación española en la frontera sur del territorio. Queriendo hacer patente al rey y sus consejeros los padecimientos de la gobernación, destaca una y otra vez "el miserable estado en que [h]oy se halla este Reyno" ${ }^{6}$. A esas alturas del primer cuarto del siglo XVIII, el esquema defensivo hispano instalado sobre la frontera del Biobío desde los días de Alonso de Ribera, y que fue reinstaurado por gobernantes posteriores tras el paréntesis que significó el proyecto de Guerra Defensiva del padre Luis de Valdivia, parecía colapsar a causa de la negligencia administrativa colonial. Factores externos y endógenos, como el apoyo cada vez más escaso en hombres y recursos desde el Virreinato del Perú, las tropas mal pagadas y mal pertrechadas, la corrupción de oficiales reales que lucraban con los recursos destinados a

4 "Carta de don Jerónimo Pietas y Garcés al rey...", Op. Cit., f. 40v.

5 En efecto, el informe de 1719 dice que "el modo de hacer guerra estos indios es el más extraño que se cuenta de nación alguna, porque desde que se declara es un enemigo duende, que jamás se le halla cuerpo ni llega a afrontarse" (Goicovich, 2007: 216).

"Carta de don Jerónimo Pietas y Garcés al rey...", Op. Cit., f. 40. 
sostener la línea de frontera, así como la dejación que creaba la rutina militar, fueron el caldo de cultivo para la gestación de un clima de complacencia y desinterés que corroía los cimientos de la autoridad que pudieran ejercer los representantes del distante poder monárquico.

Como un oriundo de España, de seguro constató con pesadumbre que la merma del poder hispano no solo era una realidad del Viejo Mundo ${ }^{7}$, ya que en estas latitudes la pauta de la relación interétnica parecía ser escrita por los nativos. En efecto, consideraba que el orgullo peninsular se veía menoscabado con la inútil práctica de los parlamentos, puesto que al asentar la paz y conservarla los gobernantes se veían en la obligación de tener que obviar las acometidas y sublevaciones que les habían precedido, concediendo a los indios todo cuanto pedían, sin importar si se trataba de requerimientos justos o injustos. Intercalando quejas sobre las decisiones erróneas que se habían tomado y casos que apoyarían su pesimista visión de las cosas, Pietas redacta un informe que más que explicar busca convencer al rey de los débiles cimientos sobre los que se sostenía la posición española en estas tierras, alertando de la necesidad de tomar un giro más radical en la política interétnica. Así, por ejemplo, denuncia que en un fallido intento de los indios por acabar con la vida del teniente general don Alonso de Córdoba y Figueroa, fueron muertos diecisiete españoles, y en lugar de castigar a los responsables se hizo un parlamento, acordando "quarenta años de treguas"8. En el gobierno de Francisco lbáñez de Peralta, las cuadrillas encabezadas por los caciques Ñamiñancu y Curilepi mataron a un teniente corregidor junto a otros españoles, pero una vez que los líderes fueron capturados se les hizo retornar a sus tierras cuando el cacique Curiquien exigió su liberación profiriendo fuertes amenazas. Bajo la regencia de Andrés de Ustáriz, los mapuches de Boroa mataron un español de Purén, a quien "cortaron la cabeza, y estubieron en voz pública alzados los indios de la tierra y los domésticos, que llamamos yanaconas", pero a fin de evitar un conflicto de incierto resultado el gobernador optó por citar "a los caciques para parlamento", en el que una vez reunidos se procuró no "[h]ablar de[l] alzamiento, por cuya causa quedaron muy soberbios y mal dispuestos los ánimos de los yndios" . Aún más incomprensible fue la atroz muerte que hicieron en las personas de quienes velaban por su salvación espiritual: los padres Nicolás Mascardi, primero, y Francisco Javier de Elguea, después, cayeron martirizados en medio de sus

7 Según Diego Barros Arana, "al terminar el siglo XVII, España había llegado al último extremo de la postración. Sus ejércitos destrozados en todas partes, su poder naval aniquilado, la hacienda pública arruinada, la industria muerta, la miseria espantosa de sus poblaciones, el abatimiento de las letras y de las ciencias..." (Barros Arana, 2000: 317). Sobre la decadencia de España en el siglo XVII, véase el interesante trabajo de Lépori de Pithod (1998).

8 "Carta de don Jerónimo Pietas y Garcés al rey...", Op. Cit., f. 41.

9 Ibíd., f. 42. 
labores apostólicas. Con Antillanca, el responsable de la primera muerte, se hizo un parlamento en Concepción, sin que se hablase una sola palabra del tema; respecto al segundo atentado, "en su tiempo no se hizo ni la menor dilijencia para castigar esta maldad" 10 , teniendo que esperar hasta la regencia de Gabriel Cano de Aponte para hacer justicia.

En la perspectiva de Pietas, las acometidas de las tribus meridionales eran el resultado inevitable de la incapacidad material y humana de las fuerzas españolas para inclinar la balanza en su favor ${ }^{11}$. Una serie de eventos desfavorables y hasta ignominiosos daban testimonio del poco peso que a esas alturas detentaba el antaño orgulloso acero español, dando por resultado una falta de autoridad frente a sus contrapartes nativas. Se queja, por ejemplo, de que los indios de Boroa impidieron que los representantes del gobernador don Juan Henríquez de Villalobos, encabezados por el sargento mayor Fernando Bascuñán, hiciesen justicia sobre un tal Pedro González que había cometido un delito grave, intercediendo para que le fuese perdonada la vida ${ }^{12}$. Algunos años más tarde el gobernador Tomás Marín de Pobeda nombró cabo de Purén a don Antonio Valenzuela, pero por no ser del gusto de los indios lo cambió a solicitud de ellos en menos de un año ${ }^{13}$. Casi al mismo tiempo las parcialidades de Purén impidieron que Juan de Novoa fuese desterrado a Chiloé ${ }^{14}$. La avilantez de los indios y la fragilidad de la posición hispana es graficada en palabras de Pietas cuando sentencia que en todo el tiempo que gobernó Marín de Pobeda "no se puso capitán de amigos que no fuese nombrado por los mismos yndios"15. Incluso detalles protocolares son presentados como evidencia de la fragilidad castellana, como fue el caso del cacique Millaquir de la reducción de Cholchol, quien en el parlamento de Concepción de 1701 rechazó indignado un obsequio del gobernador Francisco Ibáñez y Peralta aduciendo que "a un cacique como él no se le daba sombrero burdo" ${ }^{16}$. En fin, cuando recién comenzaba la regencia de Gabriel

10 lbid., f. 42v.

11 El sesgo de Pietas es rastreable en gran parte de la documentación de la época. Sin desconocer que la mala situación de la planta militar pudo ser un incentivo para las arremetidas de diversas parcialidades indígenas, no es menos válido considerar que la existencia del mismo ejército era quizás el más importante factor de dilatación de la situación bélica, dadas las constantes presiones y abusos en que incurrían muchos de sus integrantes hacia las vecinas comunidades nativas. Mención aparte merece la exagerada magnitud con que los papeles de esos días dibujaban el panorama bélico que reinaba en los bosques meridionales; a la sombra de la guerra se tejió una red de intereses que alentaba la perpetuación del conflicto, llegándose a esbozar con frecuencia un retrato más angustiante del verdaderamente existente.

12 Ibid., f. 41.

13 Ibid., f. 41v.

14 Ibidem.

15 Ibidem.

16 Ibid., f. 42v. 
Cano de Aponte, el lonko Vilumilla, junto a los nativos de la reducción de Maquegua, impidieron que las fuerzas reales llevaran preso al capitán Juan de Soto, a quien se acusaba de vivir "peor que los mismos yndios" 17, es decir, a la usanza indígena.

Los dispositivos de control espacial y humano habían sido ineficaces en sus propósitos originales. Los fuertes enclavados en el corazón del territorio indígena eran de escaso provecho, ya que "ni para adelantamiento de las armas, ni propagación de el ebanjelio servían, como se auía visto en tantos años"18. En efecto, solo una década atrás el veedor general del ejército Juan del Pozo y Silva hizo presente esta situación al rey, al afirmar que "todos los fuertes que estavan dispuestos tierra adentro para el opósito de los indios y contener sus alzamientos están destruidos, sin muros, sin arma y sin gente" ${ }^{\prime \prime}$. Junto a ello, era sumamente frecuente que las fuerzas acantonadas en el espacio fronterizo estuvieran aquejadas físicamente tanto por la vejez como por el deplorable estado de salud que resultaba de las precarias condiciones de vida al interior de las fortalezas (Villalobos, 1995: 76): el hambre y la enfermedad completaban el cuadro de devastación que creaba la guerra.

En la apreciación de Pietas, el alzamiento indígena que se iniciaba en 1723 demostraba, también, que tanto el trabajo misionero como el rol de los capitanes de amigos habían fracasado en su pretensión de someter la voluntad de los naturales mediante un trato personalizado y benévolo, como había sido el espíritu que motivó su implementación; muy por el contrario, además de representar un gasto infructuoso para la Real Hacienda, la muerte de unos u otros a manos de los rebeldes solo había servido para inflamar las llamas de las rebeliones pasadas y presentes. En este punto es a todas luces evidente el sesgo en que incurre el oficial real. Fruto de su postura hispanista templada en sus años formativos en tierra española y cruzada por una extensa red de prejuicios interiorizados en sus años al servicio de la milicia española en un contexto tan complejo como la frontera mapuche, Pietas omite el hecho de que el conflicto que se estaba gestando era precisamente el resultado de los abusos que cometían algunos capitanes de amigos ${ }^{20}$. Hombres como Pascual Delgado,

17 Ibídem.

18 Ibíd., f. 40.

19 "Carta del veedor general del ejército don Juan del Pozo y Silva a S.M. el Rey; Concepción, 10 de enero de 1713", BBMM, tomo 176, fs. 4-5.

20 En su informe de 1729, Jerónimo Pietas responsabiliza a un juego de palín como la chispa que encendió la rebelión. Durante el encuentro el capitán de amigos Pascual Delgado habría golpeado a algunos indígenas rivales, los que posteriormente asaltaron su casa en señal de venganza, matándolo a él y a sus acompañantes, el capitán de amigos de Viluco, Juan de Verdugo, y el subteniente Juan de Navia. Es muy poco probable y hasta irrisorio que una rebelión surja de las diferencias ocasionadas por un juego; más aceptable es pensar que los eventos de la justa fueron la gota que hizo rebalsar un vaso de odiosidades que se 
cuya muerte fue la chispa que desataría la rebelión, aprovechaban su calidad de intermediarios entre ambas sociedades para obtener beneficios a expensas de los nativos, entorpeciendo el comercio interétnico, generando desconfianzas y dando pie a tensiones entre indios y españoles, amenazando la paz existente en la frontera (Casanova Guarda, 1987: 37). Como bien señala Sergio Villalobos, el "negocio de la guerra" se había transformado en una formidable empresa económica, en la cual la preparación contra el potencial conflicto con el mundo mapuche no ocupaba el primer lugar (Villalobos, 1992: 89).

Finalmente, la estrategia de los parlamentos como un medio para aquietar las aguas e impedir una escalada de violencia es sopesada críticamente, siendo ponderada como una ruta equivocada de la política interétnica hispana ${ }^{21}$. El autor denuncia que los indios solo acudían por el interés que despertaban los obsequios, y no permitían el bautizo de los infantes a menos que "les diesen añil, chaquiras, agujas y otras menudenzias"22. El balance final, en suma, demostraba la precariedad de la situación española, la que no era más que el corolario del mal manejo que hasta entonces se había hecho de los recursos humanos y materiales, así como de la indecisión en la definición de una política interétnica que, dadas las circunstancias, tendría que sustentarse sobre medidas de fuerza. Como un verdadero mundo al revés, "se veía que más sujeto estaba cada uno de los gobernadores a los yndios, que ellos a los gobernadores" 23 .

\section{El comienzo de la rebelión mapuche de 1723}

Como un testigo privilegiado de los incidentes que caracterizaron a este lance fronterizo, el autor presenta una narración bastante detallada de las escaramuzas y medidas atenuantes de lo que llegaría a ser la primera rebelión mapuche del siglo XVIII. Tras la embestida ocurrida por el mes de marzo en Quechereguas que culminó con la muerte del capitán Pascual Delgado, quien "se había atraído el odio de los indios por la arrogante soberbia con que los

venían acumulando desde antiguo. Véase la "Noticia sobre las costumbres de los Araucanos, 1729", en Gay (1846: 506).

21 Pietas -al igual que la historiografía tradicional- consideraba a los parlamentos como una institución de raigambre hispana, desconociendo su naturaleza híbrida, en tanto producto de la conjunción de dos tradiciones diplomáticas asentadas sobre prácticas culturales diferentes: la indígena y la española. Sin embargo, es válido señalar que en al menos tres aspectos el Parlamento se aproxima más al mundo mapuche que al hispánico: "En primer lugar, en su aspecto ritual, que se inscribe en gran parte en la tradición indígena; en segundo lugar, en cuanto medio de comunicación interétnico que privilegia la lengua y el estilo discursivo indígenas; y, por último, como mecanismo de contacto político que se inserta coherentemente en la lógica indígena de la 'donación'" (Zavala, 2008: 160-161).

22 "Carta de don Jerónimo Pietas y Garcés al rey...", Op. Cit., f. 42.

23 Ibíd., f. 40v. 
trataba y por los castigos crueles y arbitrarios que les infligía" (Barros Arana, 2001: 28-29; Encina, 1983b: 157)24, los nativos de la costa iniciaron una serie de embestidas contra las plazas de Purén y Tucapel, robando los ganados, quemando viviendas de españoles e incluso las casas e iglesias que custodiaban los padres misioneros, "quebrando, rasgando y pateando ymajenes, cruces y sagrarios" 25 .

Por orden del gobernador, don Gabriel Cano de Aponte, el maestre de campo general Manuel de Salamanca se dirigió a fortalecer la línea del Biobío, para que "coronase sus pasos conteniendo al enemigo si intentaba pasarle" 26. Con este fin reforzó la plaza de Negrete, en el borde norte, con 300 hombres. La situación de los fuertes emplazados al meridión de este curso fluvial no era mucho mejor, puesto que "con la falta de exercito y situados, las plazas estaban sin más soldados, municiones, ni víueres que aquellos que la escasez de todo permitía" 27. Para subsanar esta falencia se empeñó en reforzar Purén con 40 milicianos $^{28}$, sitio en que los expedicionarios permanecieron cuarenta días rodeados de enemigos que asechaban a cualquiera que osara incursionar fuera de los muros.

Siguiendo la narración del texto, comprobamos que la llegada del invierno no significó una tregua para los asentamientos del sur, que fueron sometidos a un asedio constante. Jerónimo Pietas, a decir verdad, magnifica los eventos, empapado de un espíritu alarmista posible de constatar en otros papeles y crónicas. Quien más contribuyó al estudio del tema afirmó casi tres décadas atrás que "iniciada la rebelión de 1723, ella fue realzada de manera exagerada por las autoridades, produciéndose una alarma injustificada en todos los círculos del país, cuya principal explicación radica en lo inesperado que resultaba el suceso después de una prolongada estabilidad en la frontera" (Casanova Guarda, 1987: 25). Prueba de ello es que transcurridas las primeras semanas de la rebelión casi toda la población española de los alrededores de los fuertes pudo recogerse a ellos sin ser hostilizados, y los sacerdotes que misionaban en sus cercanías fueron avisados de los propios indios para que se pusieran a resguardo (Encina, 1983b: 158). En resumidas cuentas, el

24 Francisco Antonio Encina es aún más explícito en este punto cuando señala: "Entre los capitanes de amigos más odiados, figuraba el de los indios de Quechereguas, Pascual Delgado. Su carácter duro y atrabiliario le había enajenado la voluntad general de los indios que gobernaba, los cuales, sobreexcitados por la efervescencia ambiente y los vapores del alcohol, lo asesinaron en la madrugada del 9 de marzo de 1723, conjuntamente con el capitán de amigos Verdugo y el teniente Juan Navia, que se le habían reunido para ir juntos a Concepción" (1983b: 157).

25 "Carta de don Jerónimo Pietas y Garcés al rey...", Op. Cit., f. 43v.

26 Ibíd., f. 44.

27 Ibidem.

28 Encina señala 62 hombres (1983b: 158). 
alzamiento de 1723 no alcanzó de ninguna manera las proporciones y los efectos de las rebeliones indígenas precedentes, se trató de un suceso parcial que si bien alteró los ánimos y concitó la atención de la población hispana, fue la consecuencia de un efecto psicológico provocado por un ambiente inesperadamente alterado en el que a esas alturas predominaba la paz.

Esta apreciación no obsta, sin embargo, el reconocimiento de estallidos de violencia localizada. Así vemos que el atrevimiento de los indios fue capaz de encauzar incursiones al norte del Biobío, específicamente en el mes de agosto de aquel año, asolando los páramos y valles montañosos de la Isla de la Laja. El maestre de campo Manuel de Salamanca salió al encuentro de la fuerza invasora que amenazaba las estancias del pie de monte cordillerano -a esas alturas casi todas desoladas como medida defensiva para impedir el robo de ganados-, hallándola en las inmediaciones del río Duqueco; a pesar de que una torrencial lluvia imposibilitó el uso de las armas de fuego, la victoria estuvo del lado de los cristianos, aunque solo se trató de una escaramuza menor en que se confabuló la oscuridad de la noche para permitir la huida de la mayoría de los alzados ${ }^{29}$. Jerónimo Pietas, sobrevalorando una victoria de poca cuantía, afirma que "no [h]ay duda que este suzeso [h]a detenido al enemigo para que no se atreba a pasar a estos partidos" 30 .

Un triunfo menor como éste no apaciguó las llamas de la inquietud, puesto que los habitantes de los centros poblados sentían un profundo recelo de los indios domésticos o yanaconas, quienes estaban emparentados con los rebeldes y, por tanto, sobre los que recaían sospechas de traición. En un suceso que aún no ha recibido la suficiente atención de los historiadores ${ }^{31}$, surgió el rumor de una alianza entre los indígenas sometidos de los obispados de Santiago y Concepción y los mapuches del sur del Biobío. El corregidor de Chillán, Domingo León, comunicó al gobernador el 23 de agosto que había hecho prisioneros a diez yanaconas, los que "ha descubierto que están confederados con los de la tierra adentro, siendo sus designios dar avance a esa plaza luego que la gente saliese a la expedición proyectada para la primavera; que la coalición es general, habiéndose huido diversos indios de las estancias, y que le avisan se juntan en la cordillera de Illico a fin de armarse y aviarse" ${ }^{\prime \prime 2}$. En la capital y apenas un mes y medio más tarde, tras

29 "Carta de don Antonio de Urrutia al Presidente; Estancia de Beltrán, agosto de 1723", en Medina (1952: 488).

30 "Carta de don Jerónimo Pietas y Garcés al rey...", Op. Cit., f. 46.

31 Los cultores de la Historia de las Mentalidades han producido interesantes trabajos sobre el estudio del concepto del tiempo en la era colonial, el rol de los ritos y las fiestas, o el pánico producido por las catástrofes naturales. El miedo y la paranoia gestados en las rebeliones indígenas es un campo aún por explorar.

32 "Carta del corregidor de Chillán Domingo León al gobernador del Reino de Chile; Chillán, 23 de agosto de 1723", en Medina (1952: 486-487). 
un plenario del 1 de octubre, la Real Audiencia comunicó al gobernador el 6 de dicho mes que en las cercanías de Melipilla "en los cerros llamados de Meringue se habían reunido hasta mil lanzas, proponiéndose sorprender al pueblo de Santiago en la Cañada, donde estarían en la noche presenciando los fuegos que se quemarían en honor de San Francisco [...] se trajeron presos más de cien indios de todos los alrededores"33. La preocupación cundió en las ciudades del norte del Reino, cuyos habitantes encomendaron sus vidas haciendo "rogatibas y nobenas en las mas de sus yglesias", y procuraron reforzar la seguridad de los centros poblados "con estacadas y parapetos" 34 .

El temor a perder los fuertes transfronterizos y la necesidad de reforzar la línea del Biobío, hizo indispensable la convocación del Consejo de Guerra a principios de agosto. Gabriel Cano de Aponte propuso el desmantelamiento de las fortalezas y su traslado al borde septentrional, conformando una línea militar de seis presidios que servirían de llave para la seguridad del Reino, impidiendo las incursiones mapuches al otro lado del curso fluvial. En el mes de octubre se procedió a evacuar los presidios de la planicie costera, San Pedro, Colcura, Arauco y Tucapel, y en diciembre fue el turno de Santa Juana, Nacimiento y Purén (Casanova Guarda, 1987: 30; Zavala, 2008: 108).

Poco después se iniciaron las labores de construcción de los nuevos establecimientos, los que conservaron los nombres de sus predecesores. Holdenis Casanova es quien mejor grafica estas tareas

"En el delta formado por los ríos Duqueco y Biobío, a orillas de este último, se levantó el fuerte de Purén. Diez leguas más abajo, siempre al norte del Biobío y casi frente del lugar donde había existido el fuerte de Nacimiento, se construyó otro con el mismo nombre. Más al poniente, en las alturas de Hualpén, casi en la desembocadura, se estableció otro fuerte con el nombre de Arauco, que solo subsistió algunos años. Por último, cerca de la cordillera, al norte del río de La Laja, se fundó Tucapel, para cerrar el paso de los pehuenches a las tierras de los españoles" (Casanova Guarda, 1987: 30).

El proyecto contó con adherentes y detractores, pero es indudable que el fortalecimiento de la línea del Biobío dio mayor tranquilidad a las poblaciones del norte. Así y todo, Pietas deja en claro que abrigaba pocas esperanzas de victoria ante un eventual enfrentamiento formal de las mermadas e indisciplinadas milicias hispanas contra las mucho más numerosas fuerzas indígenas. Una situación apremiante como ésta obligaría al gobernador a recurrir a la

33 "Carta de la Real Audiencia al gobernador; Santiago, 6 de octubre de 1723", en Medina (1952: 494).

34 "Carta de don Jerónimo Pietas y Garcés al rey...", Op. Cit., f. 46. 
criticada política de los pactos, pero solo como una estrategia dilatoria que permitiera al rey el envío de un refuerzo de 400 o 500 hombres, que habrían de ser imprescindibles para inclinar la balanza del lado español.

Ponemos a disposición de los especialistas esta importante fuente que tiene el doble mérito de arrojar luces tanto de la situación fronteriza española a comienzos del siglo XVIII, como de la pesimista visión de un hombre sobre el precario equilibrio que mantenían las fuerzas hispanas con el mundo indígena. En la transcripción del documento, que forma parte de los Manuscritos Originales de la Colección José Toribio Medina resguardada en la Biblioteca Nacional de Santiago de Chile, se modernizó la ortografía y la puntuación, para hacerlo más asequible a los investigadores.

\section{Carta de don Jerónimo Pietas y Garcés al Rey sobre la guerra de Arauco y el estado general del Reino de Chile. Chillán, 3 de octubre de $1723^{35}$}

Señor:

Viendo el miserable estado en que hoy se halla este Reino, adonde ha[ce] cuarenta y dos años que vine de esos de España, y que lo miro ya como patria propia, por estar casado y cimentado en él, y siendo (para mayor gloria suya) uno de los del dominio de Vuestra Majestad, solicita el celo de este leal vasallo hacer el postrer esfuerzo en buscar el remedio, poniendo patentes a los reales ojos y piadosos oídos de Vuestra Majestad nuestros trabajos y lamentos, y la ocasión de padecerlos. Ruego a su Divina Majestad sean más dichosas estas mis letras en llegar a las reales manos de Vuestra Majestad, que lo fueron las que en dos ocasiones escribió mi leal celo, pues conozco que de haber llegado no nos viéramos los de este Reino temiendo el lamentable fin, que ya este año hubiéramos tenido a no ser por el pronto remedio que explicaré cuando refiera el estado de él, porque en mis antecedentes discursos prevenía como antevistos los sucesos presentes. En el primer año que gobernó este Reino Don Francisco Ibáñez de Peralta, me pidió un informe de toda esta frontera para enviarlo a Vuestra Majestad, y en él entre las cosas que escribí de la naturaleza, ritos, aversión a los españoles y inconstancia de estos indios ponderaba lo inútiles que eran y habían sido desde la conquista de este Reino las Plazas de Purén, Tucapel y Arauco, internadas más de veinte leguas en las tierras de los indios, pues ni para adelantamiento de las armas, ni propagación del evangelio servían, como se había visto en tantos años, estando los indios

35 Sala Medina, Documentos Originales, tomo 309, documento 82. 
peores cuantos más iban corriendo. Y lo mismo decía de los capitanes de amigos y de las misiones, pues las plazas solo servían de aumentar gastos a la Real [H]acienda, en la conclusión tan dilatada de víveres y pertrechos, y de dar muchos cuidados a los gobernadores en el tiempo de sublevaciones de los indios que anualmente las intentaban los capitanes, de que tuviesen aquellas cabezas por suyas los indios, siempre que las quisiesen. Y las misiones, de que estuviesen padeciendo y inutilizándose aquellos religiosos, y gastando cantidad de la Hacienda Real sin que sacasen fruto alguno de sus trabajos.

En otro informe que me pidió de cómo hacían la guerra y cómo se sentaba y mantenía la paz, cuando hicieron algunas muertes de españoles los indios, escribí sus traiciones y astucias, y expliqué la extraña forma de su guerra, cual no se ve en otra nación alguna pues para ser ejército copioso, era un enemigo duende que nunca se le hallaba cuerpo ni se afrontaba; y para un corto trozo de gente era una ave de rapiña que por los aires se lo llevaba entre las garras. Así mismo expliqué que con lo que se sentaba la paz y se conservaba, era con sufrir todos los que habían gobernado muchas indignidades, como son disimular sus sublevaciones, aunque llegasen a hacer muertes de españoles, sentarlos a la mesa, conceder cuanto pedían fuese justo o injusto, no poner cabos ni capitanes sino los que ellos querían, y en fin dándoles gusto en todo, en que se veía que más sujeto estaba cada uno de los gobernadores a los indios, que ellos a los gobernadores. Y para prueba de esta verdad, aunque me dilate pondré algunos casos sucedidos en mi tiempo, y algunos de ellos sucedidos cuando estaban en este Reino dos ministros del Consejo de Vuestra Majestad que se hallan en esa Corte, don Diego de Zúñiga y Tobar, y Don Gonzalo Baquedano, quienes me conocen y pueden testificarlo. Gobernando este Reino don Juan Enríquez, era don Alonso de Córdoba y Figueroa teniente general de la caballería y cabo de la plaza de Purén; y viniendo de Repocura a su plaza, salieron muchos indios armados a quitarle la vida, y aunque no encontraron con él, porque siempre se recelaba aunque estaba de paz la tierra, y andaba por caminos encubiertos, mataron a los españoles y capitanes que toparon, que fueron diez y siete. Y la satisfacción que se cogió habiendo entonces buen ejército, fue hacer un parlamento, capitulando el gobernador con los indios algunas condiciones, y entre ellas la de cuarenta años de treguas. Ese mismo gobernador ordenó al sargento mayor del Reino, que lo era don Fernando Bascuñán, fuese a Boroa y quitase la vida a Pedro González por un delito grave, y los caciques lo impidieron, y contra toda justicia le hicieron el gobernador lo perdonase. Siendo gobernador don José de Garro, porque los indios no querían otro, mantuvo de cabo de Purén y comisario de naciones los ocho años de su gobierno a Bartolomé Pérez de Villagra, y saliendo como salió dos veces con todo el ejército a parlamentar y capitular haciendo junta general de caciques. Yo, aunque entonces era mozo, le dije hablando solos que no era de razón que el príncipe capitulase con sus vasallos, y que pues su santidad había concedido a nuestro rey y señor 
el derecho positivo de todo lo conquistado en la América, y esta tierra lo había sido, como se veía en las ciudades perdidas, y estos indios habían sido sus vasallos y eran rebelados, les intimase lo que conviniese y no capitulase, pues solo de monarca a monarca se hacían capitulaciones. Y me respondió [que] no podía él faltar a lo que su antecesor había acostumbrado. Siendo gobernador don Tomás Marín de Poveda, puso de cabo de Purén a don Antonio Valenzuela, y por no ser a gusto de los indios lo reformó a pedimento de ellos antes del año en este mismo gobierno. Sobre sacar algunos brujos refugiados en Maquegua, se fortalecieron con estacada los indios, y yendo a esta función el comisario de naciones que lo era don Antonio Pedreros con tres mil indios amigos y algunos españoles, lo mataron y al capitán Miguel de Quiroga, y no se cogió más satisfacción que salir el gobernador con todo el ejército, que se componía de mil y ochocientos arreglados y setecientos milicianos, y parlamentar y capitular con los caciques. En todo su tiempo no se puso capitán de amigos que no fuese nombrado por los mismos indios. También quiso desterrar a Chiloé por tierra a don Juan de Noboa, y habiéndolo sacado de Purén no quisieron los indios dejar pasarlo, y pausó su destierro. Siendo gobernador don Francisco lbáñez de Peralta, las cuadrillas del cacique Ñamiñanca y Curilepi mataron al teniente corregidor Guevara, que lo era de Mendoza, y otros españoles; y habiendo tenido presos en Arauco a los dos caciques, por que los pidió con amenazas el cacique Curiquién, se los entregaron sin darles ni la menor reprensión. Ese mismo año Guichavitún y Antepangue, el de Maquegua, mataron otros españoles y trajeron cautivo un mulato esclavo que yo saqué, y todo se disimuló. Era ese año corregidor de la Concepción don Diego de Zúñiga y Tobar. Siendo Gobernador don Andrés de Ustáriz mataron a un español de Purén los indios de Boroa y le cortaron la cabeza, y estuvieron en voz pública alzados los indios de la tierra, y los domésticos, que llamamos yanaconas, de los cuales, presos algunos por el maestro de campo general, fueron ajusticiados y hechos cuartos. Y sintiendo mucho el gobernador se dijese había alzamiento, mandó a los cabos de la frontera citasen a los caciques para parlamento, y ellos, dándoles algunos dones a los que no querían salir, y en particular a Vilumilla, los juntaron y se hizo el parlamento, sin hablar de[l] alzamiento, por cuya causa quedaron muy soberbios y mal dispuestos los ánimos de los indios. De esta manera se ha mantenido la paz, disimulando los gobernadores porque no se dijese había en su tiempo alzamiento, y los cabos de las plazas por sus intereses y tratos con ellos, y no habrá quien diga que un año tan solo los ha visto que obren y procedan como leales vasallos, ni que hayan recibido padre[s] misioneros por deseo de entrar en la fe, sino por el vino que les habían de beber, ni que hayan querido se bautizase ningún parvulillo, sin que les diesen añil, chaquiras, agujas y otras menudencias. Y de no confesar esto, que diga cualquiera de los padres que han sido misioneros, si sin llevar estas cosas podían salir a correr la misión. Notorio es también que mataron en Nahuelhuapi al padre Nicolás Mascardi, y cuando el gobernador don Francisco Ibáñez hizo parlamento 
en la ciudad de la Concepción, que fue el primer año de su gobierno, vino a él el cacique Antillanca que fue el que lo mató, y no se le habló en ello ni una palabra, con nota de los dichos caciques. También en este parlamento, dándole el gobernador un sombrero al cacique Millaquir de la reducción de Cholchol, lo arrojó diciéndole que a un cacique como él no se le daba sombrero burdo, y el gobernador calló y le dio otro.

Siendo gobernador el doctor don José de la Concha, mataron en Nahuelhuapi al padre Francisco Javier de Elguea y a un mozo y un niño que le acompañaban, y en su tiempo no se hizo ni la menor diligencia para castigar esta maldad. Entró en el gobierno el que actualmente está, don Gabriel Cano de Aponte, quien luego que supo este caso mandó al general de la Provincia de Chiloé enviase a castigar aquellos indios, como así se ejecutó, y mataron al cacique y otros y se ahuyentaron los demás. En el principio también de este gobierno el sargento mayor del Reino, que lo era don Pedro de Acuña, envió unos soldados a Maquegua a prender al capitán Juan de Soto, que lo era de aquella reducción, porque vivía peor que los mismos indios. Y trayéndolo preso envió Vilumilla muchos indios con armas, y lo quitaron. $Y$ en medio de sufrirles tanto, si no hubiera habido en todos esos tiempos ejército que los contuviese, ni un año tan solo hubiera durado la paz, pues raro ha sido aquel en que no han intentado alzarse.

Estas cosas no especulaba el que afirmó no era necesario ejército en Chile, por cuyos mal discurridos consejos se miran, y este Reino tan afligido como se verá cuando refiera el estado en que se halla. Ojalá el que fue causa de que se disminuyese el ejército se hallara gobernándolo, que ahora vería si es todo uno, ser gran hombre en leyes y en las universidades, o entender el arte militar, y si puede tener acierto quien en facultad que no es de su profesión da pareceres.

Impresionado ya el virrey del Perú por estos informes, no ser necesario ejército en este Reino, se niega a enviar gente de aquél, según se ha reconocido en haber llegado tres navíos al puerto de la Concepción del de el Callao, y no enviar en ellos gente alguna, aunque se le ha pedido con la instancia que en tan urgente lance se requiere. Esto ha causado tal confusión en toda esta frontera, y en particular en esta ciudad por haber sido dos veces saqueada en otros alzamientos, que solo se clama al cielo para el pronto remedio, pues no le hay en la tierra; y aunque el gobernador haya sido, como todos dicen, buen soldado, y como se conoce en sus disposiciones, ¿qué ha de hacer sin gente y sin dinero? Habiendo hallado estas plazas tan desmanteladas, que en las más de ellas se cerraban las puertas en los cuerpos de guardia por no haber quien hiciese posta en las armas, y muchos trechos de los lienzos de las murallas caídos. Esto ha podido enmendarlo, pero no remediarlo, porque depende de otra voluntad. 
Y porque en la alta consideración de Vuestra Majestad tengan acogida estas verdades, que las digo como uno de los leales vasallos que haber puede en la Monarquía, y como quien según mis años no puedo tardarme en ir a dar cuenta a Dios, pintaré el estado actual del Reino. Desde el mes de marzo de este presente año que fue en el que sucedieron las muertes de los capitanes en la reducción de Quechereguas, incesantemente han estado los indios dando avances a las plazas de Purén y Tucapel, porque ayudando su muchedumbre a tener por todas partes prontas operaciones, unos acudían a los robos de ganados y quemas de las casas de los españoles que vivían entre ellos, otros a las iglesias y casas de los padres misioneros, donde entraban quebrando, rasgando y pateando imágenes, cruces y sagrarios, y montando a caballo con ellos formar escaramuzas con muchas risadas y escarnios. Otros a forzar a alzarse a los indios que no querían, diciéndoles los matarían si no cogían las armas. Y Dios permitió estas separaciones para que tuviese tiempo don Manuel de Salamanca, que era y es maestro de campo general y gobernador de las armas, de juntar alguna gente de las milicias más cercanas, y con ochenta arreglados que sacó de la Concepción sin perder punto a la prontitud que el caso requería, dando luego aviso al capitán general que se hallaba en la ciudad de Santiago, se puso en la plaza de Yumbel, desde donde le ordenó al corregidor de esta ciudad le despachase las milicias de su jurisdicción. El gobernador, luego que recibió el aviso, hizo varios despachos a juntar las milicias de todos los partidos con orden que a toda marcha saliesen para la frontera, y escribió al maestro de campo general saliese al río de Biobío y coronase sus pasos, conteniendo al enemigo si intentaba pasarle, y si adquiría noticia de que la plaza de Purén corría riesgo, la socorriese a todo trance, cautelándose en todo cuanto viese convenía. Mientras él se ponía en la frontera, el maestro de campo general, luego que recibió esta orden salió para Biobío y puso trecientos hombres en Negrete, que es donde por aquel tiempo tiene vado, y sabiendo se hallaba en gran peligro la plaza de Purén, porque había sufrido tres asaltos en término de dos días de tres mil indios, donde obró más el divino favor, como se vio en el sudor de Nuestra Señora y otros santos, que las fuerzas humanas, porque como ya he dicho a Vuestra Majestad, con la falta de ejército y situados las plazas estaban sin más soldados, municiones, ni víveres que aquellos que la escasez de todo permitía. Supo asimismo estaban ya tan sin municiones que apenas podrían sufrir otro asalto, por lo cual adelantó a todo riesgo en una trasnochada cuarenta hombres con algunas municiones, y cogió la marcha para la plaza con cuatrocientos, sin llevar más bocas de fuego que las de los arreglados, porque la gente de las milicias de este Reino no sabe manejarlas. Las espías de los sitiadores les dieron aviso, y ellos, por enviar a juntar más gente, se retiraron tres leguas de distancia con su campo, con que tuvo lugar el maestro de campo general de entrar en la plaza sin combate alguno. El gobernador se detuvo diez días por la lentitud que tuvo el Real Acuerdo en dar algún dinero para el mantenimiento de las milicias y los demás gastos urgentes; 
que entonces, siendo la primera noticia de la sublevación la tuviesen no es de admirar, pero que ahora estando en tantos aprietos se excusen a darlo con tanta porfía que hagan parar todas las disposiciones de salir a campaña no lo mira el Real Acuerdo con buen acuerdo. Pasados los diez días corriendo la posta se puso en esta frontera, y siendo ya llegada la estación del invierno, con continuas lluvias, arribó al río de Biobío y pasó al fuerte del Nacimiento, donde se detuvo porque supo que el enemigo con la noticia de su llegada se fue a las montañas, donde era imposible seguirlo sin hacer función alguna, por las continuas lluvias, lo invadeable de muchos ríos y la debilidad de los caballos fatigados de tan largas marchas. Desde allí dio las providencias necesarias para que se llevasen víveres a Purén y quedase bien abastecida la plaza para toda la invernada y parte del verano, y envió orden al maestro de campo general se retirase, dejando doscientos hombres de guarnición en ella, entre milicianos y arreglados, que allí estaba para favorecerle en la retirada y pasaje del río si los indios dispusiesen venir a embarazarle. Todo se ejecutó sin azar alguno, y habiendo llegado a Yumbel despidió las milicias con orden estuviesen apercibidos y prontos para la primavera salir a campaña. No se hubiera ejecutado esto con tanta felicidad, si no hubiera sido con la prontitud que se hizo, porque el enemigo, como era alzamiento forzado, no tuvo lugar de que criase cuerpo su campo; bien se ha reconocido después, pues cundiendo el fuego por toda la tierra, han hecho toda la invernada sin cesar diversas hostilidades, teniendo gente bastante para embestir y cercar a un tiempo mismo las tres plazas internadas en sus tierras y los fuertes del Nacimiento y Santa Juana, y echar a esta banda de Biobío mil y quinientos indios. Este orgullo y este atrevimiento no se cuenta lo hayan tenido en los antiguos alzamientos, y se reconoce era, porque había entonces ejército cuyo respeto los contenía. Llegado el aviso de haber pasado los indios a esta parte de Biobío a la Concepción, donde ha tenido su invernada el gobernador, envió luego al maestro de campo general con algunos arreglados a Yumbel, y hizo despacho a los corregidor[es] de esta ciudad y la estancia del Rey, para que con la brevedad que el caso pedía juntasen las milicias, y las despachasen a Yumbel. Hicieron de su parte los corregidores cuanto pudieron para juntarlas, más como las lluvias eran continuas y los ríos venían hechos mares no les fue posible juntar sino muy poca gente.

El maestro de campo general, teniendo repetidos avisos de las corredurías de los indios entre los ríos de la Laja y Biobío, y que aunque en aquella isla no había ganado alguno, porque previniendo el riesgo mandó el gobernador se despoblase y sacasen todos los ganados de ella, recelándose no intentasen pasar la Laja y entrar a los partidos habiéndosele juntado doscientos milicianos, quiso mostrarse al enemigo para ponerlo en algún recelo y contenerlo, y con esta resolución salió a campaña y pasó el río de la Laja. Yo siempre he tenido esta salida por arr[i]esgado arrojo, más su divina Majestad permitió le fuese mejor de lo que se podía esperar, porque queriéndose alojar en 
unas casas y corrales junto a un río llamado Duqueco, diez leguas distante de Yumbel, sin que los batidores hubiesen visto indio alguno, habiendo ya los más desensillado sus caballos, avisó una de las centinelas de campaña venían muchos indios acercándose, y llamado a otros por señas con las manos el maestro de campo, que aún tenía ensillado su caballo, salió por sí con algunos acompañados a reconocerlos, y viéndolos ya a tiro de artillería se fue retirando sin apresurarse por dar lugar a que todos ensillasen, y hizo se pusiesen separados unos de otros entre las casas y corrales, porque pareciese más cuerpo de gente que la que llevaba. Llegó el enemigo tendiéndose en forma de media luna, y aunque llegaron a tiro no se pudo usar de las bocas de fuego por la gran lluvia que estaba cayendo y humedad de la pólvora, pues hecha la experiencia los mejores fusiles no prendían. Viéndose ya precisado por no mostrar flaqueza al enemigo, mandó embestir, que lo hicieron con tal furia que los indios, como la lluvia ayudaba a obscurecerse el día, que ya era cerca del toque de la oración, discurriendo sería mayor el número de los españoles, echaron a huir a todo correr. Fueron los nuestros picándoles la retaguardia y matando algunos, hasta que el maestro de campo los contuvo con el recelo de que no fuese aquella huida maliciosa, por alejarlos de las casas y corrales. En ellas pasó la noche con los caballos ensillados, y llegado el día hizo reconocer la campaña, y hallándola desierta se retiró con sosegadas marchas a Yumbel, donde hoy se halla. No hay duda que este suceso ha detenido al enemigo para que no se atreva a pasar a estos partidos, pero si los indios hubieran reconocido el corto número de españoles, se puede asegurar no hubiera quedado quien viniese a contar el suceso. Con estas tribulaciones se ha pasado todo el invierno sin que haya habido un día de sosiego, empleándose en las ciudades en rogativas y novenas en las más de sus iglesias, y en fortalecerse con estacadas y parapetos.

El día de hoy se halla la plaza de Purén cercada de seis mil indios con tal tenacidad, que dicen han de morir todos en el cerco, o han de morir los cercados de hambre, y que no temen las amenazas del gobernador ni a los españoles, pues tienen harta gente que los ataje. A la plaza de Tucapel le han dado muchas embestidas con desesperado denuedo, cegando el foso con atados de ramas sin temor de las balas, que les hirieron a pecho descubierto y les mataron tantos que se retiraron con pérdida de muchos indios. Fue socorrida introduciendo en una trasnochada cuarenta hombres con algunas municiones. Arauco no está cercado, pero los más días se ponen indios a la vista echando grandes retos y amenazas. A los fuertes de Santa Juana y el Nacimiento han dado sus embestidas, y viendo morían muchos se han retirado. Este es el estado en que se hallan las plazas, y estando tan distantes unas de otras haber a un mismo tiempo sitiadores para todas muestra la multitud que hay de este gentío. Entre los domésticos, que se llaman yanaconas, se han hallado algunos complicados; este daño es el que se puede temer en mayor grado, porque siendo preciso por la falta de arreglados juntar las milicias, 
quedan las estancias y ganados entregados a ellos y a su arbitrio, y que cosa hay que no se deba temer siendo los más de los yanaconas procedidos de los rebeldes, donde tienen sus padres, tíos, hermanos y parientes, y estar sembrados y esparcidos por todo el Reino.

Un correo de a pie por entre las montañas me dice ha llegado de Tucapel, con quien avisa el cabo de la plaza se halla ya sin bastimento, por cuyo motivo envía el gobernador al maestro de campo con la gente necesaria a sacarla de la plaza y la de Arauco, y ponerla de esta banda de Biobío. Mientras, está entendiendo en algunas prevenciones necesarias aquí nunca vistas, puercos espines, granadas y otros artificios que suplan la falta de gente, porque de la parte donde se esperaban mil y cuatrocientos hombres no vienen quinientos, y lo mismo sucede de los demás partidos, porque se han escondido o se han huido. Y por esta razón, para reclutar este ejército siempre se traía gente de España o de Quito, porque los de este Reino no se desertan, y como tiene trecientas leguas de longitud, ha menester un preboste cada uno, o nunca parecen.

Luego que vuelva el maestro de campo, me dicen sale el gobernador con todas prevenciones a correr la tierra en busca de los rebeldes y sacar la gente de Purén y coronar de fuertes el río de Biobío, que sirva de llave a la seguridad del Reino. Confieso es la mejor deliberación que en tan urgente aprieto se puede coger, y que cesarán los riesgos en tanto que las milicias estuvieren juntas, y el gobernador se hallare con ellas en campaña; pero llegado el tiempo preciso de soltarlos para las labores de campaña, sin las cuales es imposible mantenerse el Reino, volverán a entrar los sustos, los rebatos y aflicciones, porque los fuertes que necesita el río de Biobío para que esté coronado desde la cordillera hasta el mar son seis, estando cuatro leguas distante uno de otro, y algunos seis. De más de estos el tercio de Yumbel, el presidio de la Concepción y el de esta ciudad, los arreglados son muy pocos, pues aunque en las listas de la Veeduría hay setecientos, los doscientos sirven en la Provincia de Chiloé y puerto de Valparaíso, otros ciento entre enfermos, viejos, carteros, artilleros, potrerizos y vaqueros se embeben, pues con cuatrocientos hombres, ¿qué guarnición se puede poner en cada una, si se han de repartir en nueve plazas y fuertes, para que si se arrojan al río, como se puede temer cinco o seis mil indios, pueda haber quien los contenga, pues no hará poco cada uno de los cabos de defender su fuerte dentro de su muralla? Juntar las milicias de repente es impracticable estando tan distantes, y con la confusión y pavor de oír vienen los indios, en vez de juntarse cada uno solicitará huir por librarse, como ya se ha visto en otras ocasiones, y ahora se ve en ésta, con que sin embarazo podrán entrar los indios y correr como fuego voraz todas las campañas, matando, quemando y arrasando cuanto toparen, cercar y quemar las ciudades, como se vio en las pérdidas de la Imperial, Osorno, Villa Rica y Colhue. No lo permita Dios que tal suceda, pero mucho lo temo si el virrey del Perú en estos cinco o seis 
meses no envía alguna gente sobre la cual me aseguran le hace el gobernador grandes instancias.

Este es el estado miserable en que se halla este Reino, y pues Dios no desprecia los justos ruegos de los pequeñuelos, yo uno de ellos puesto a los reales pies de Vuestra Majestad le pido como a señor de este Reino no permita se pierda, como a príncipe piadoso defienda la vida de tan humildes y leales vasallos que en él habitamos, y como a monarca tan católico, remedie que tantos templos en que se celebra sirvan de pastar las bestias, como se ve en los de las ciudades perdidas, ni que tantos templos vivos de monjas casadas y doncellas que reciben a Cristo, Señor Nuestro, en sus pechos, sirvan de pasto a la lascivia de estos bárbaros.

No le es a Monarca tan poderoso difícil el remedio, pues todo consiste en que Vuestra Majestad envíe de ese Reino cuatrocientos o quinientos hombres con sus armas, pues en la gente de éste ya se ha reconocido no son para manejar bocas de fuego ni para el trabajo, porque la misma abundancia de él, y hallar comida de balde en todas partes les ha hecho se críen ansiosísimos, y que los que vinieren a gobernar sean soldados, y muy experimentados, pues se ha reconocido en esta sublevación que si hubiera sido en tiempo de gobernador que no lo fuese, según la muchedumbre el orgullo y arresto de los indios, cual no se ha visto jamás, se hubiera perdido el Reino y en medio de no haber ejército con las prontas disposiciones atendiendo a cortar el fuego por todas partes hasta ahora (gracias a Dios) no se ha perdido nada.

Asegúranme, dice el gobernador, ha de seguir la guerra y castigar los indios, mas sin ejército dudo pueda conseguirlo, y no hará poco si los contiene, pues temo se ha de ver precisado a pactar algunas treguas dando tiempo a que Vuestra Majestad envíe gente de esos Reinos y mande al virrey envíe de las provincias de Quito la restante hasta ponerse el ejército en mil y quinientos arreglados, que serán los bastantes con esta nueva disposición de coronar a Biobío, no solo para la seguridad del Reino sino para que en breves años, haciendo entradas a maloquearlos y talarles los campos, vengan humildes a rendir total obediencia con que se pongan en pueblos y se fenezca la guerra de Chile.

Pido con humildad a Vuestra Majestad no desprecie estas verdades que ha producido mi leal celo como el más experimentado en esta frontera, y que tengo a los indios muy penetrados, porque he aprendido su idioma, corrido todas sus tierras, y tratádolos muchos años. Dios nuestro Señor mueva la voluntad de Vuestra Majestad y guarde su real y católica persona como la cristiandad ha menester. De esta ciudad de San Bartolomé de Chillán, octubre 3 de 1723.

Señor Jerónimo Pietas Garcés [rúbrica] 


\section{Referencias bibliográficas}

\section{Fuentes primarias}

\section{a) Documentales}

"Carta de don Jerónimo Pietas y Garcés al rey sobre la Guerra de Arauco y el estado general del Reino de Chile; Chillán, 3 de octubre de 1723", en Biblioteca Nacional de Chile, Manuscritos Originales de José Toribio Medina (BNOM), tomo 309 , fs. 39-47v.

"Carta del veedor general del ejército don Juan del Pozo y Silva a S.M. el Rey; Concepción, 10 de enero de 1713", Biblioteca Nacional de Chile, Manuscritos Medina (BNMM), tomo 176, fs. 4-5.

"Instrucción que se da al Comisario General don Diego de Encalada, Procurador nombrado por el ejército de este Reino de Chile para que pase a España a representar al Rey el nuevo alzamiento de los indios de él, y las calamidades que padece dicho ejército en la falta de paga y gente para las guarniciones de las plazas, defensa y conservación del Reino; Concepción, noviembre 12 de 1723", en Biblioteca Nacional de Chile Manuscritos Medina (BNMM), tomo 180-181, fs. 167-182.

\section{b) Impresas}

Goicovich, F. (2005). "Un informe inédito de Jerónimo Pietas sobre los indios del Reino de Chile, 1719", en Cuadernos de Historia 24, Departamento de Ciencias Históricas, Universidad de Chile, pp. 207-224.

León, D. "Carta del corregidor de Chillán Domingo León al gobernador del Reino de Chile; Chillán, 23 de agosto de 1723", en Medina, J.T. (1952), Cosas de la Colonia, $2^{\text {a }}$ edición. Santiago: Fondo Histórico y Bibliográfico José Toribio Medina, pp. 486-487.

Pietas, J. "Noticia sobre las costumbres de los araucanos, 1729", en Gay, C. (1846), Historia Física y Política de Chile, tomo I (documentos). París: En casa del autor, pp. 486-512.

Real Audiencia. "Carta de la Real Audiencia al gobernador; Santiago, 6 de octubre de 1723", en Medina, J.T. (1952), Cosas de la Colonia, 2a edición, Santiago: Fondo Histórico y Bibliográfico José Toribio Medina, pp. 494-495.

Urrutia, A. "Carta de don Antonio de Urrutia al Presidente; Estancia de Beltrán,

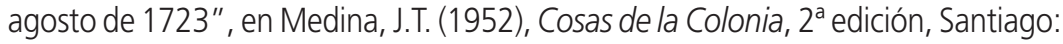
Fondo Histórico y Bibliográfico José Toribio Medina, p. 488. 


\section{Fuentes secundarias}

Barros Arana, D. (2000). Historia General de Chile, tomo V. Santiago: Editorial Universitaria/Centro de Investigaciones Diego Barros Arana.

Barros Arana, D. (2001). Historia General de Chile, tomo VI. Santiago: Editorial Universitaria/Centro de Investigaciones Diego Barros Arana.

Casanova Guarda, H. (1987). Las rebeliones araucanas del siglo XVIII. Mito y realidad. Temuco: Ediciones Universidad de La Frontera.

Encina, F. A. (1983a). Historia de Chile, tomo VI. Santiago: Editorial Ercilla.

Encina, F.A. (1983b). Historia de Chile, tomo VII. Santiago: Editorial Ercilla.

Goicovich, F. (2007). "Entre la conquista y la consolidación fronteriza: dispositivos de poder hispánico en los bosques meridionales del Reino de Chile durante la Etapa de Transición (1598-1683)", en Historia 40, vol. II, Instituto de Historia, Pontificia Universidad Católica de Chile, pp. 311-332.

Lépori de Pithod, M.E. (1998). La imagen de España en el siglo XVII: percepción y decadencia. Mendoza: Universidad Nacional de Cuyo.

Medina, J.T. (1906). Diccionario Biográfico Colonial de Chile. Santiago: Imprenta Elzeviriana.

Villalobos, S. (1992). La vida fronteriza en Chile. Madrid: MAPFRE.

Villalobos, S. (1995). Vida fronteriza en la Araucanía. El mito de la Guerra de Arauco. Santiago: Editorial Andrés Bello.

Zavala, J.M. (2008). Los mapuches del siglo XVIII. Dinámica interétnica y estrategias de resistencia. Santiago: Editorial Universidad Bolivariana. 